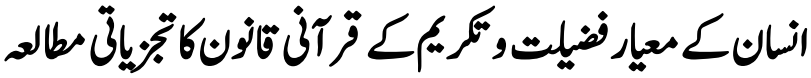

\section{Analytical Study of the Qur'anic Law of Standard for Human's Virtue and Dignity}

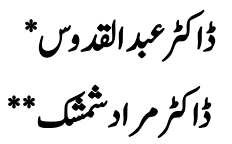

\begin{abstract}
The purpose of society in Islam is also based on respect, dignity, justice, love and endurance of mankind and Islam has not laid down any such principle or rule from the very first day to teach good speech and character. That which is contrary to humanity without any distinction. Morality should be a criterion, by which a person can be known, what is his status? Because man is created from two things, one is the external dimension, which we see as these organs. The other is the internal dimension, which is apparently invisible and this is the soul. In both of them there is both good and evil. Unless all the limbs are beautiful they are not called beautiful, in the same way unless all the habits are good they are not called good morals.
\end{abstract}

Islam is the principal religion of humanity and the greatness of humanity. Islam teaches peace, security and love, not hatred and murder, because Allah Almighty has granted the honor to a human being in among all creatures. All human beings are equal as human beings as all human beings are made of dust. Therefore, to consider the division of all humanity on earth on religious, national, regional and linguistic grounds as a criterion of superiority is a threat to humanity itself because these are the stimuluses' and causes that why human beings themselves suffer from humiliation, disgrace and contempt at the hands of other human beings. In this paper all the relevant has been described in detail.

Keywords: Human beings, Standard, Superiority, Virtue, Dignity, Qur'an

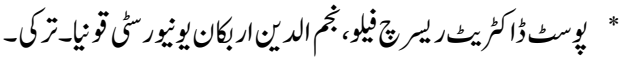

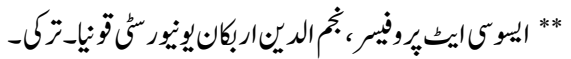




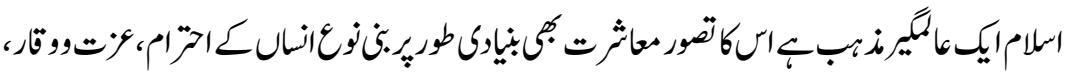

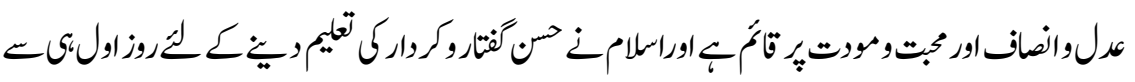

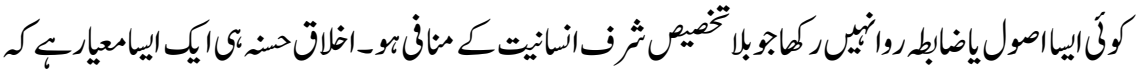

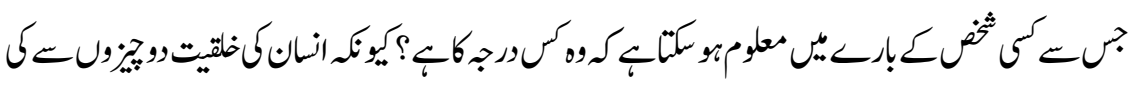

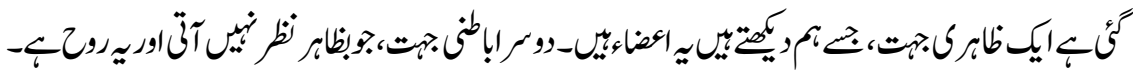

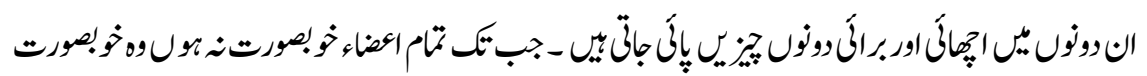

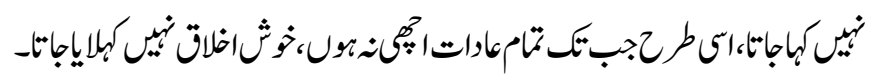

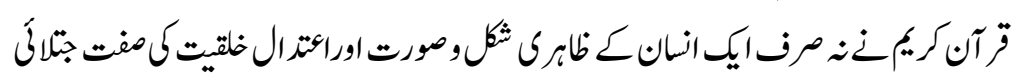

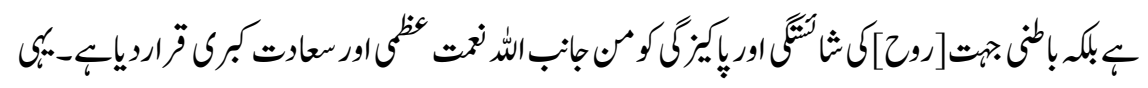

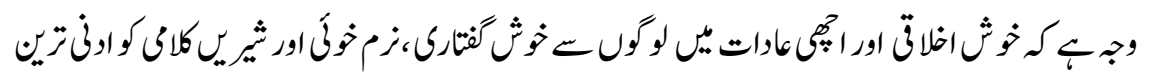

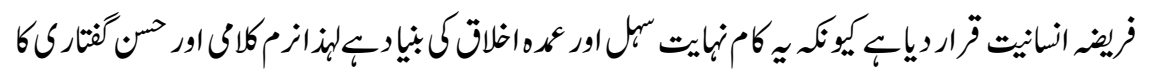

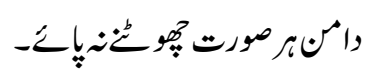

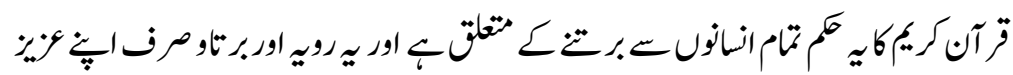

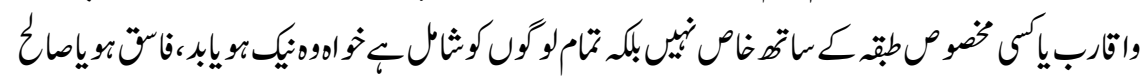

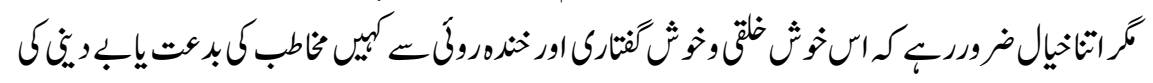

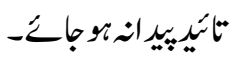

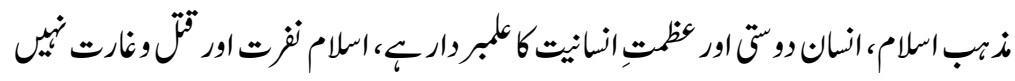

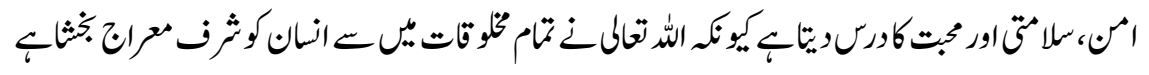

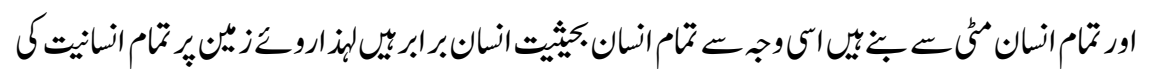

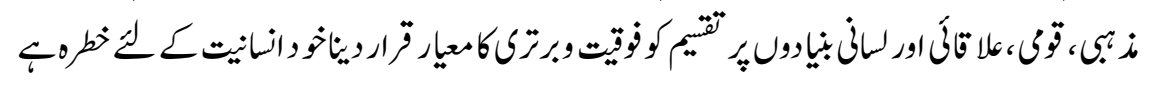

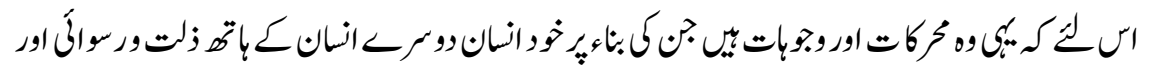

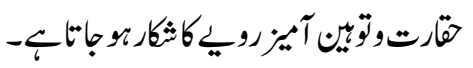




\section{لنظا انسانك تخيّنومغهوم}

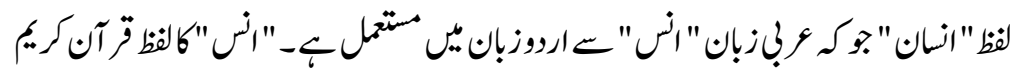

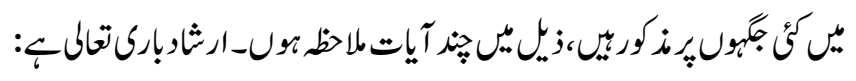

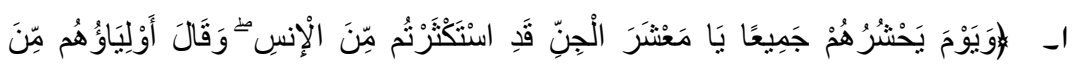

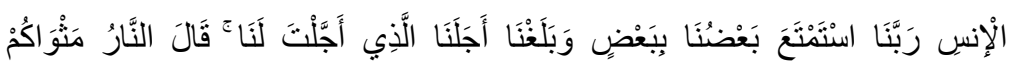

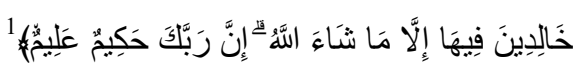

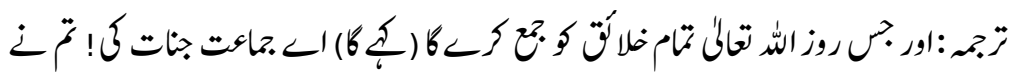

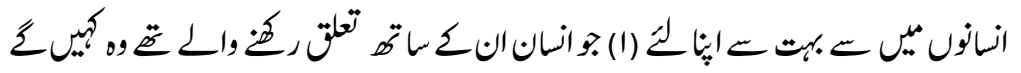

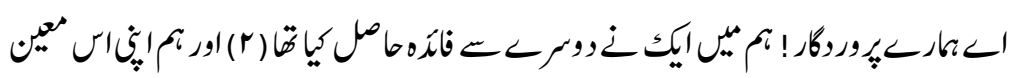

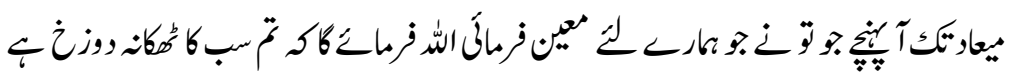

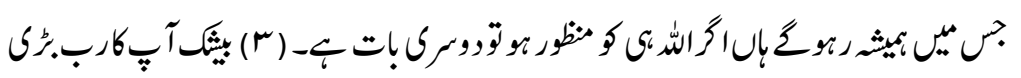

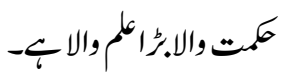

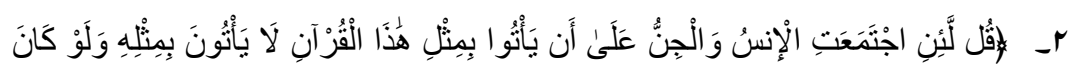

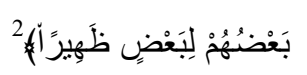

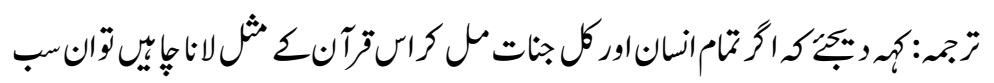

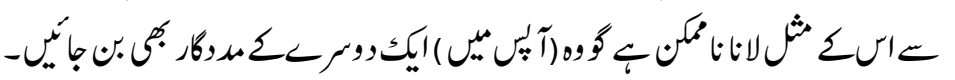

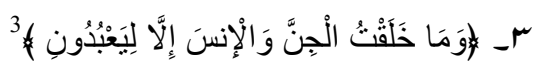

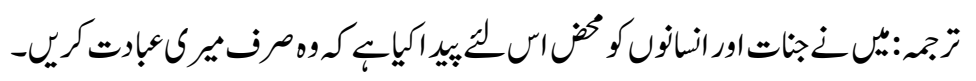

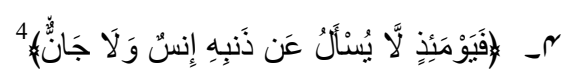

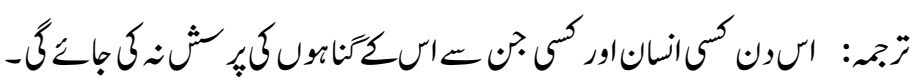

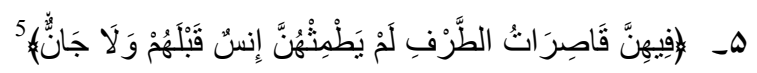

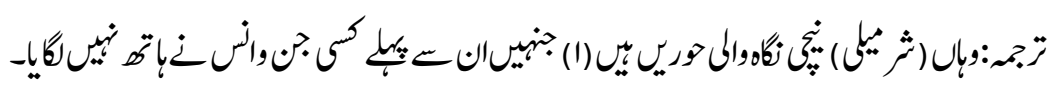




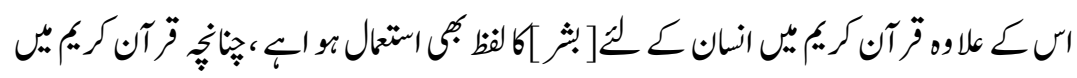
ارثاوبارك تحالكب

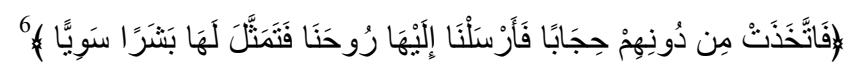

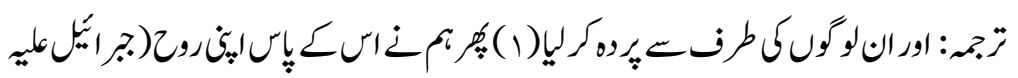

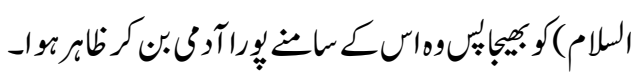

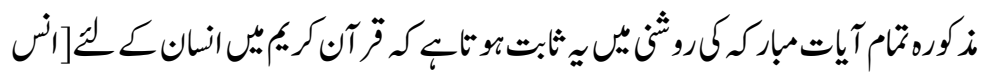

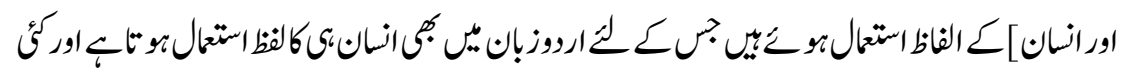

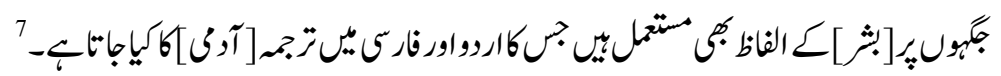

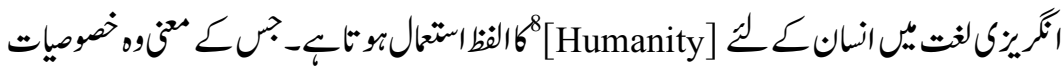

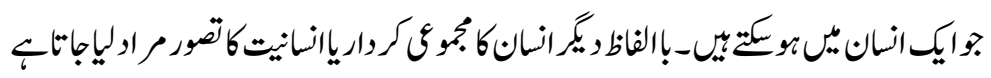

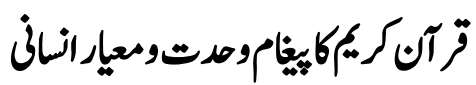

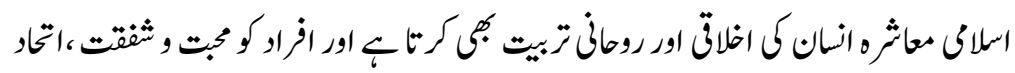

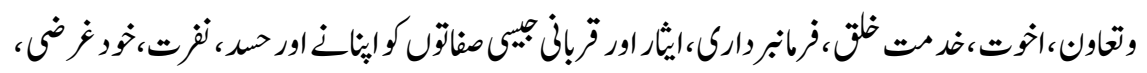

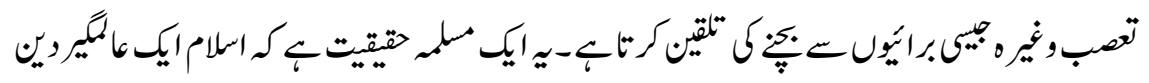

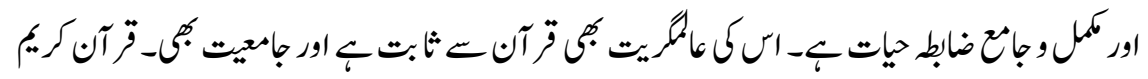

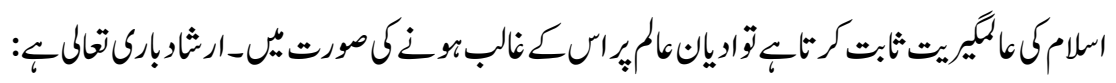

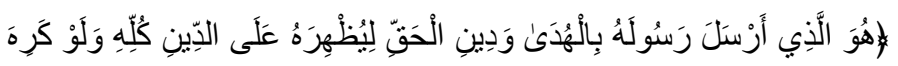

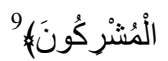

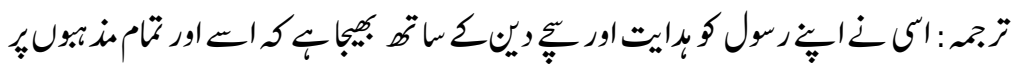

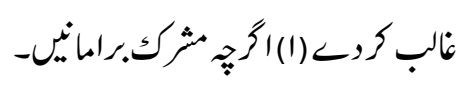




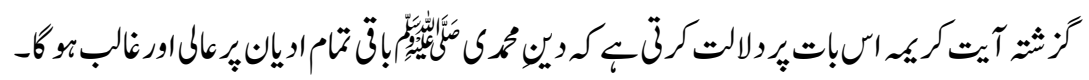

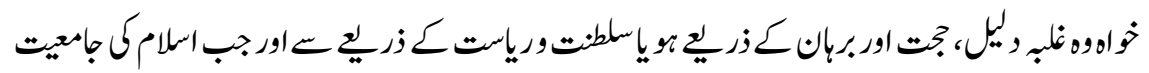

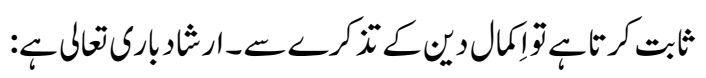

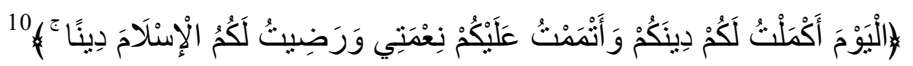

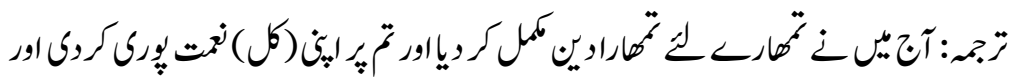

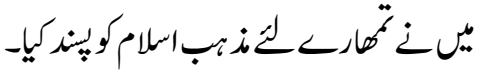

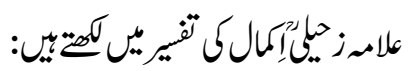

(والمراد بالا كمال: اتمامه في نفسه وفى ظهوره اما اتمامه فى نفسه فباشتماله على

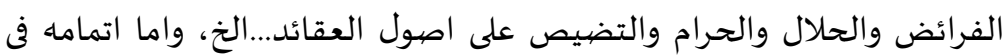

ظهوره فباعلا وكلمته وتفوقه على كل الاديان و تفوقه مع المصالج العامة)

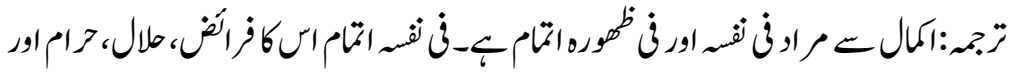

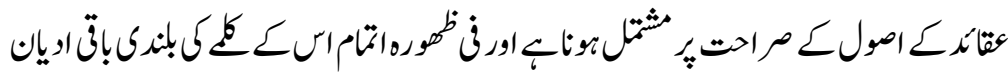

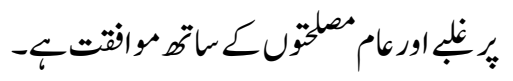

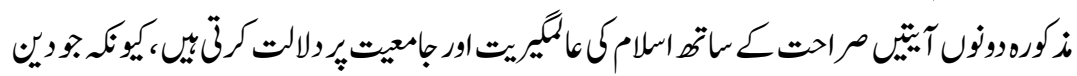

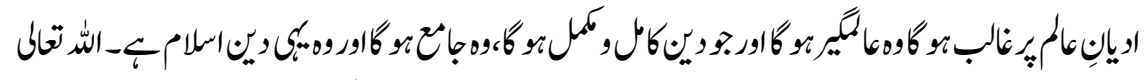

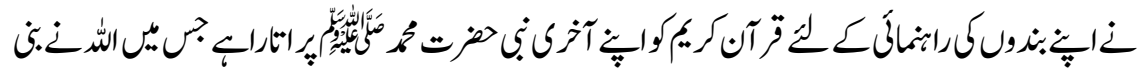

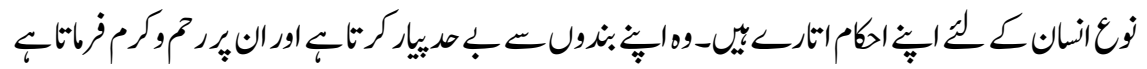

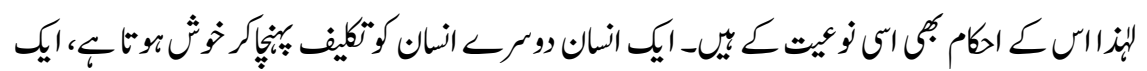

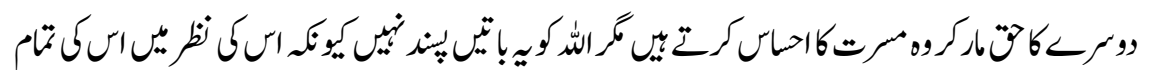

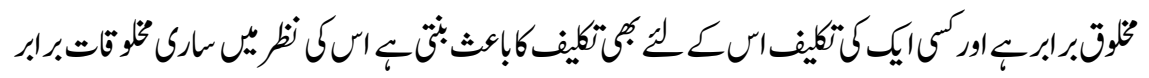

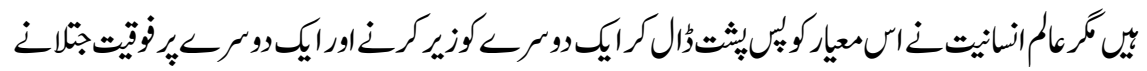

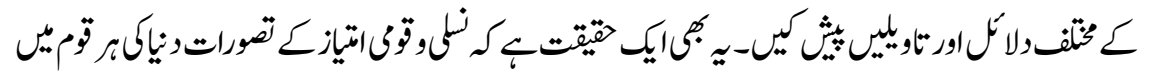

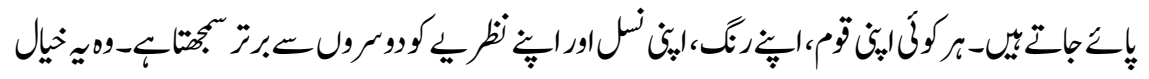

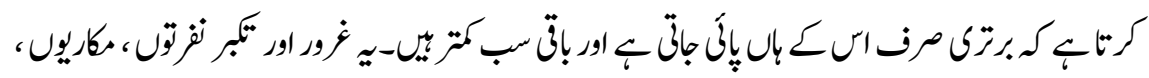




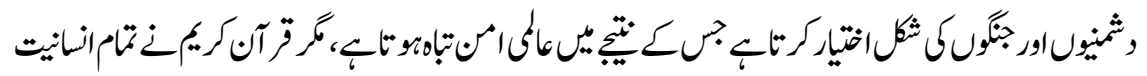

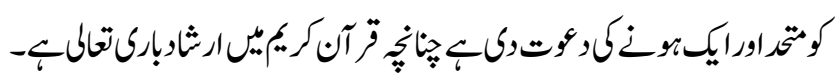

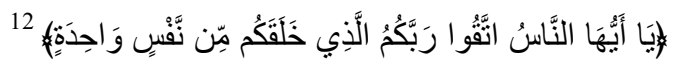

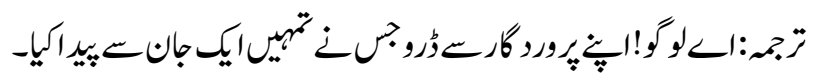

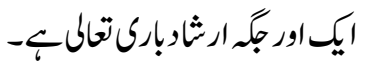

${ }^{14}$

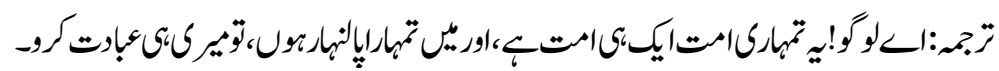

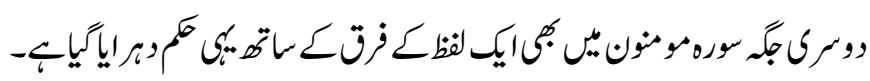

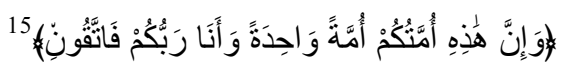

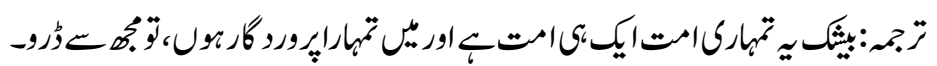

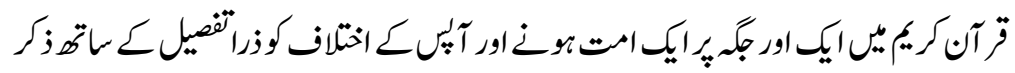

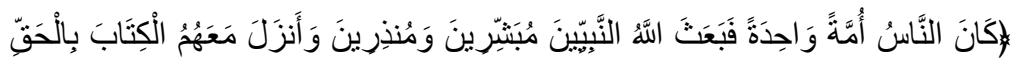

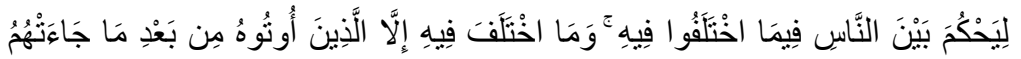

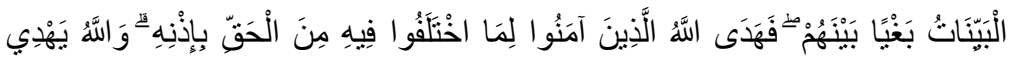

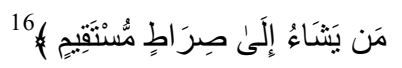

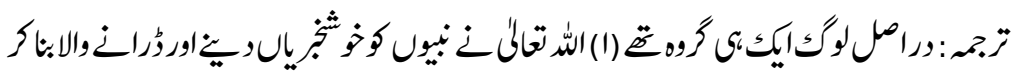

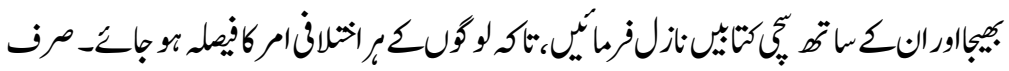

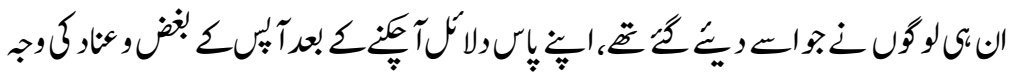

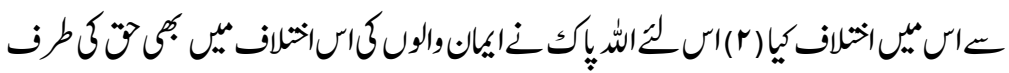

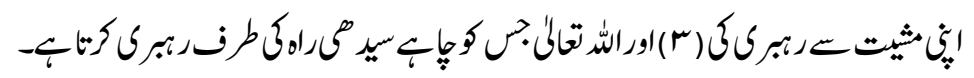




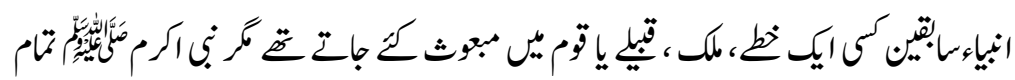

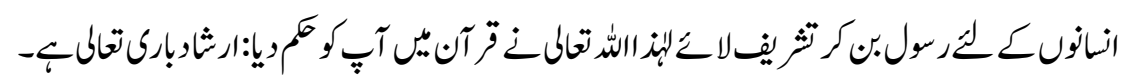

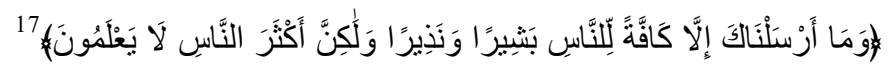

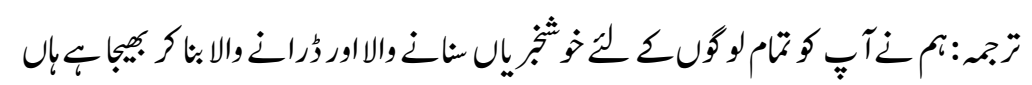

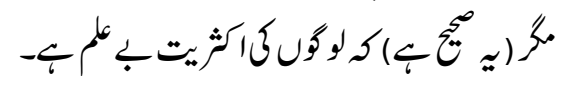

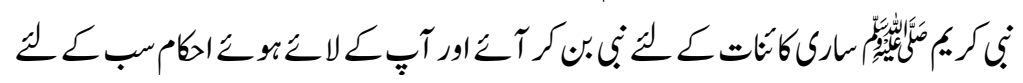

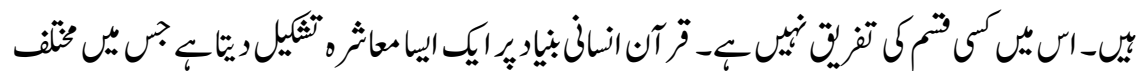

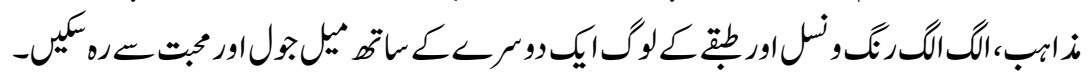

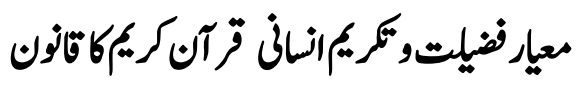

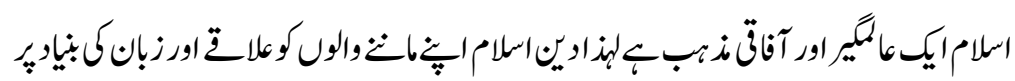

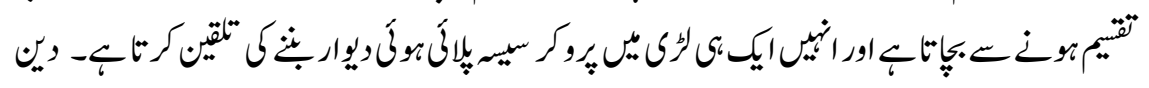

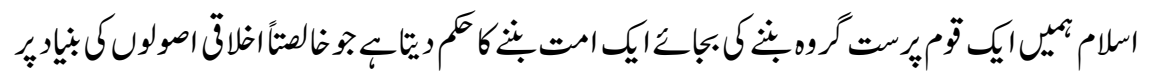

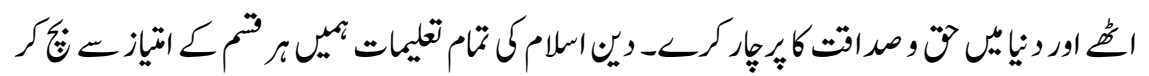

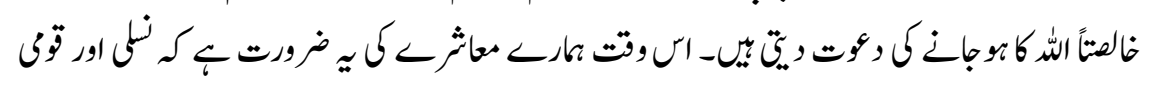

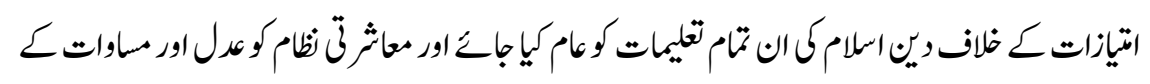

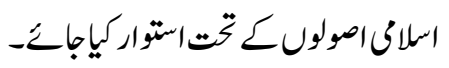

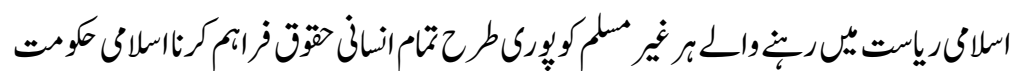

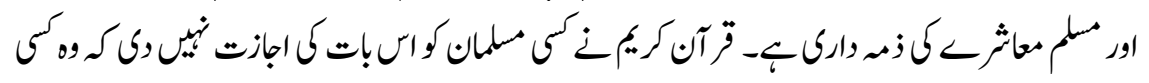

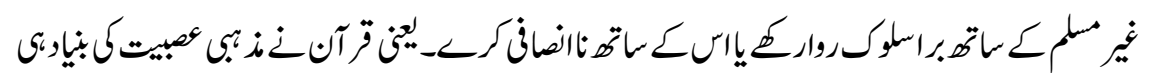

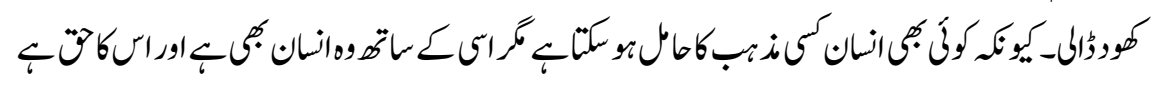

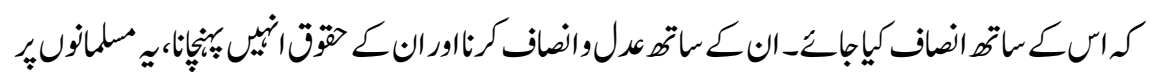

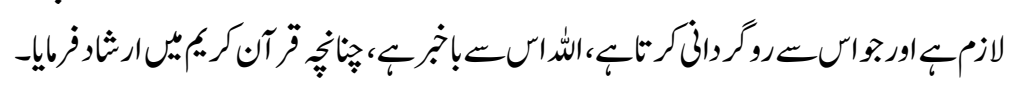

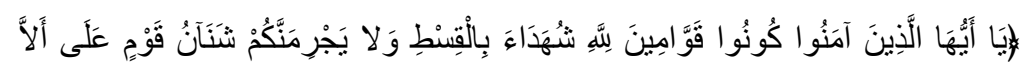

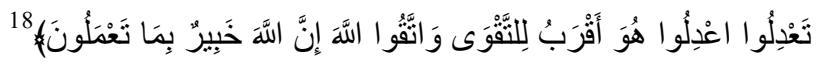




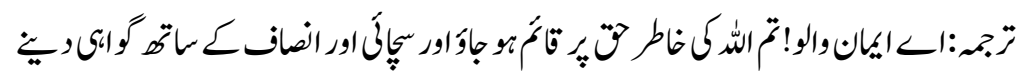

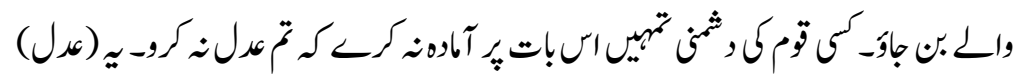

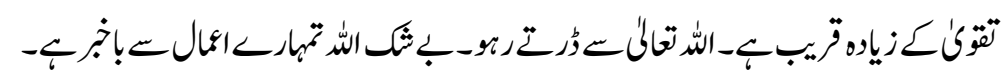

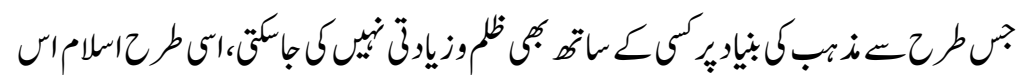

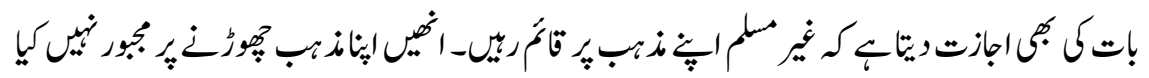

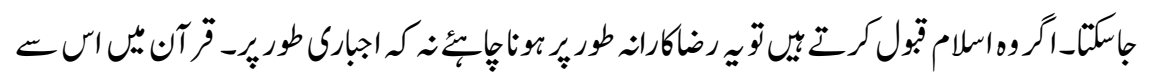
متطق بجى فرايا:

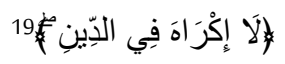

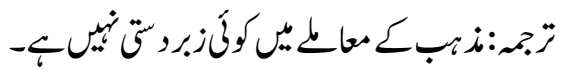

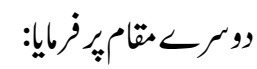
${ }^{20}$

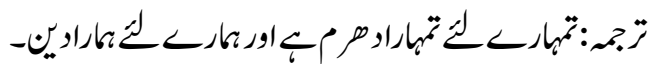

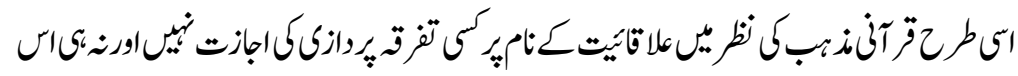

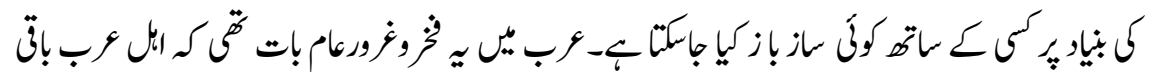

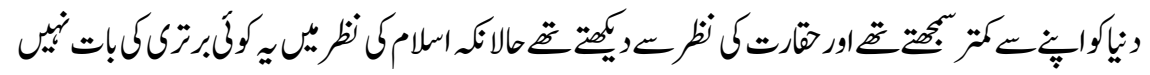

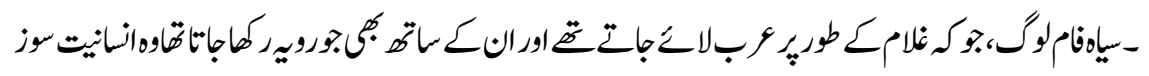

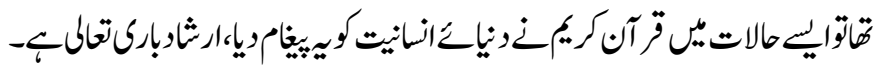

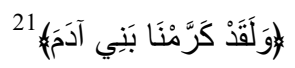

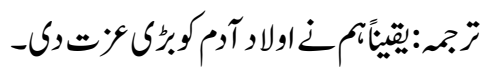

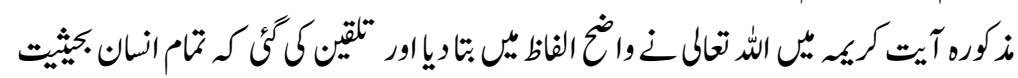

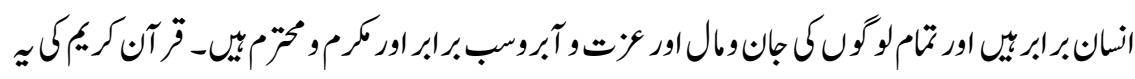

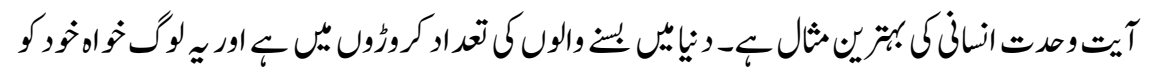

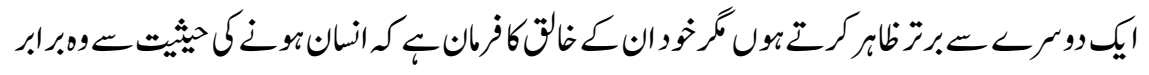




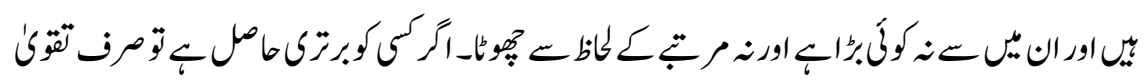

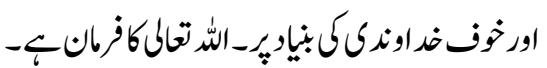

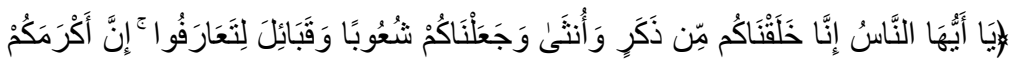

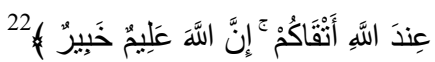

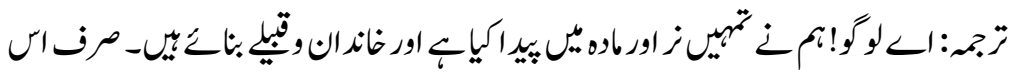

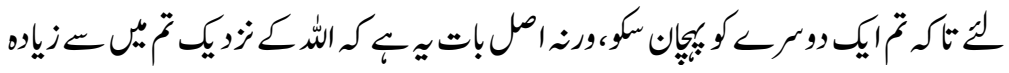

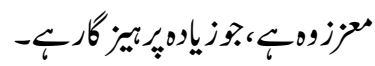

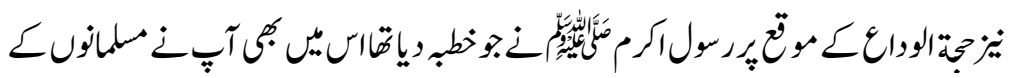

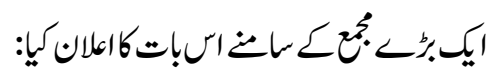

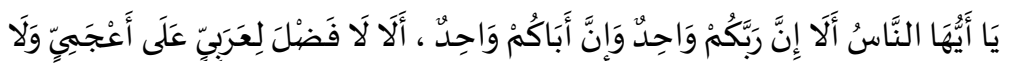

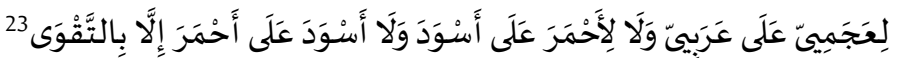

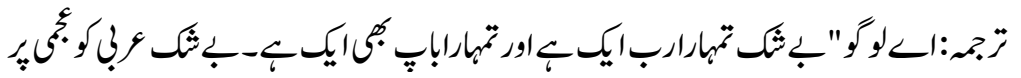

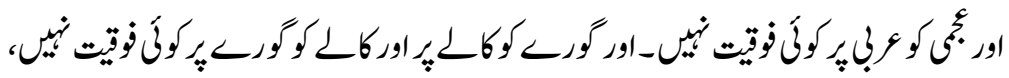
مواح تقوىك-

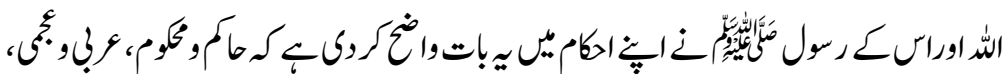

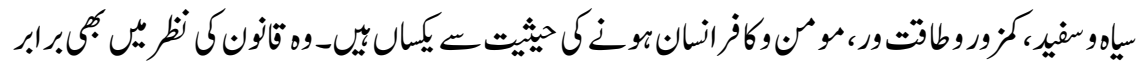

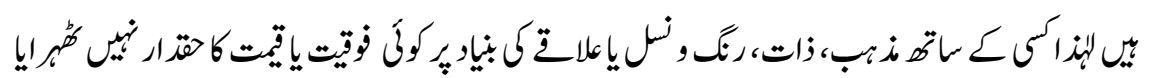

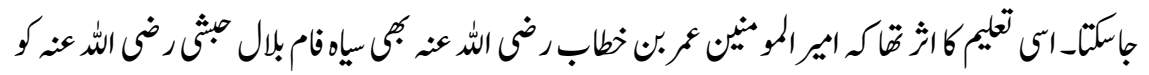

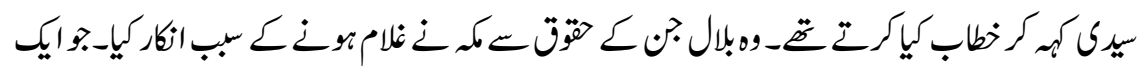

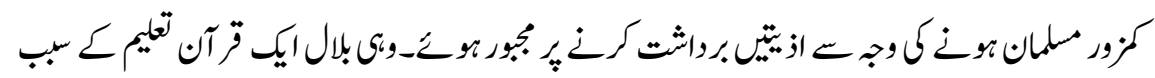

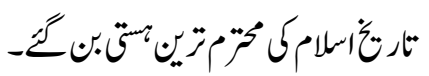

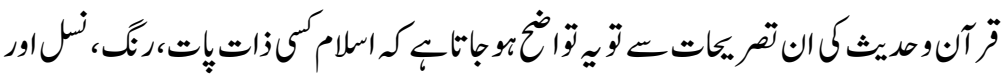

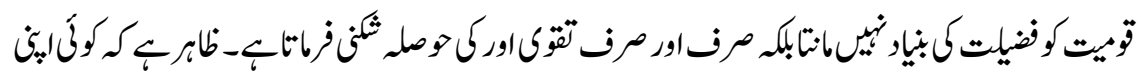

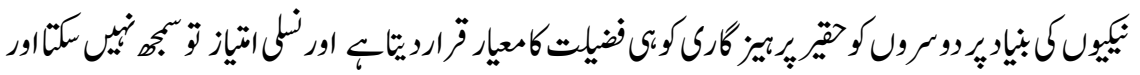




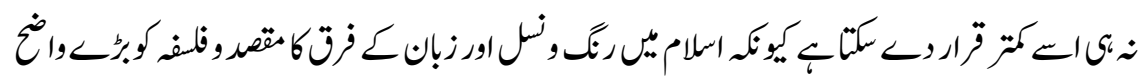

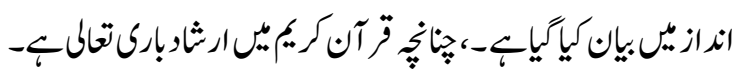

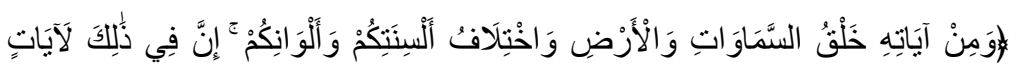

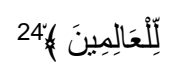

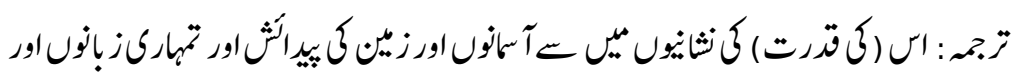

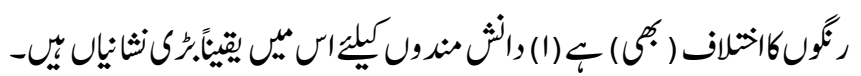

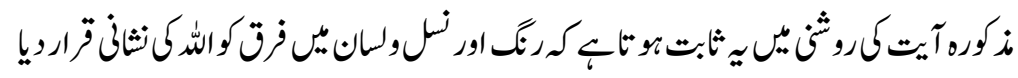

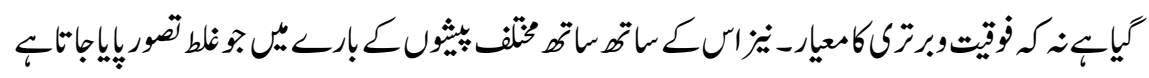

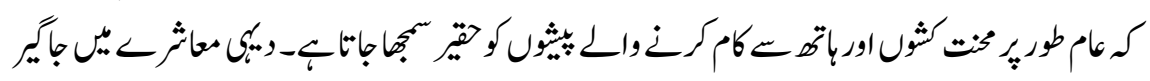

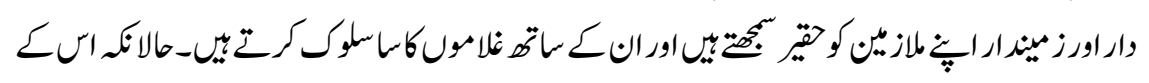

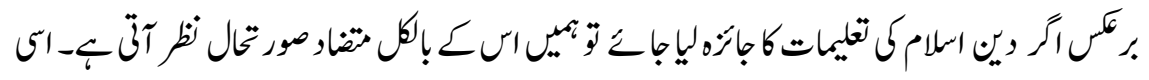

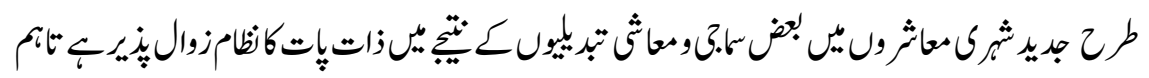

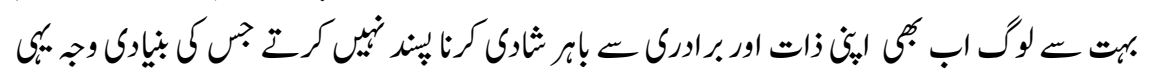

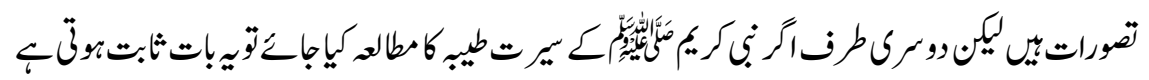

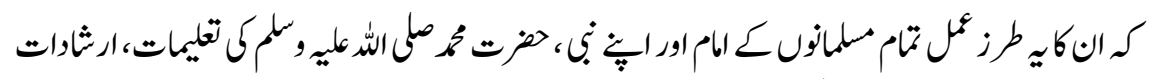

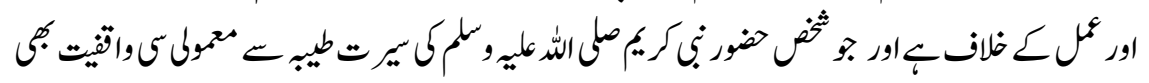

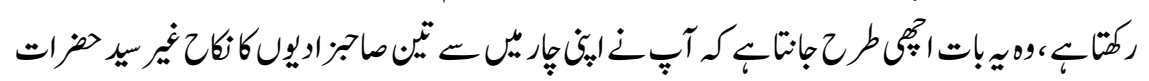

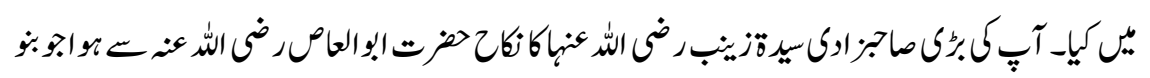

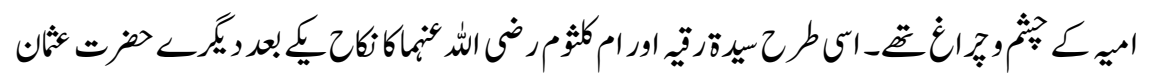

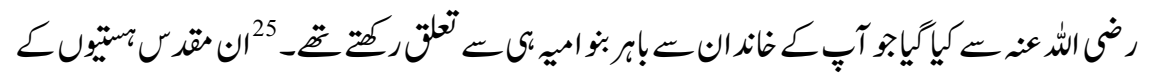

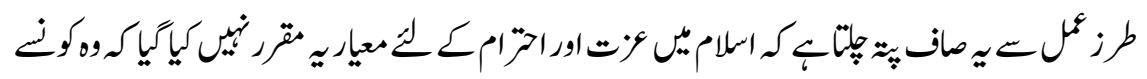

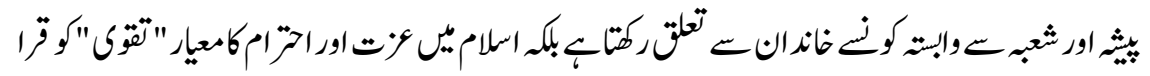

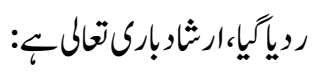




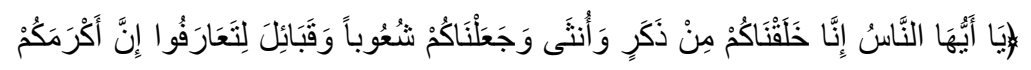

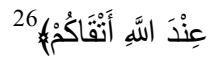

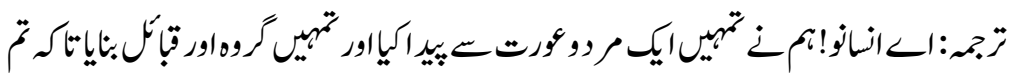

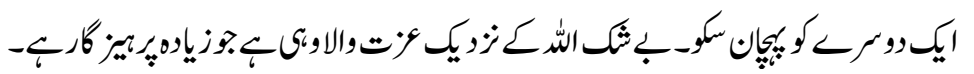

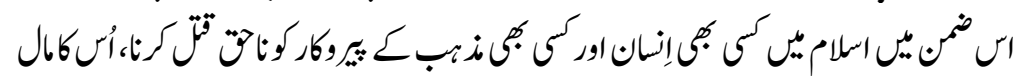

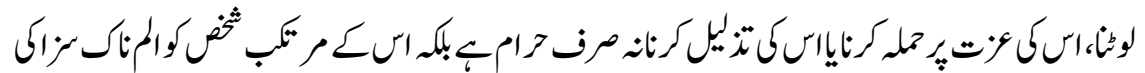

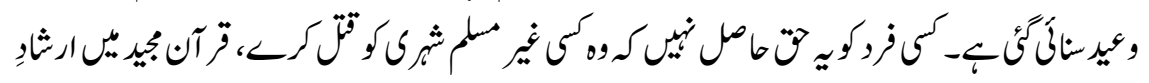

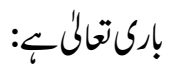

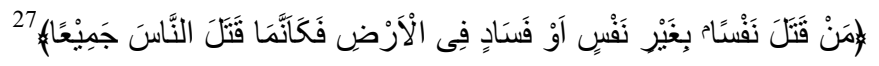

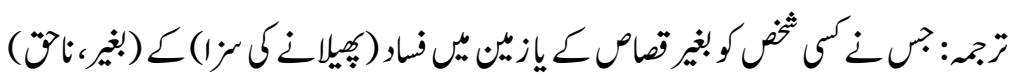

$$
\begin{aligned}
& \text { تقز كرياتوكوياسن }
\end{aligned}
$$

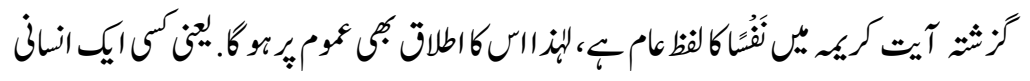

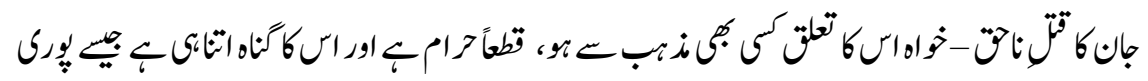

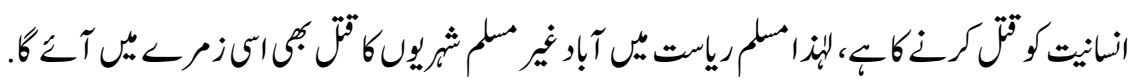

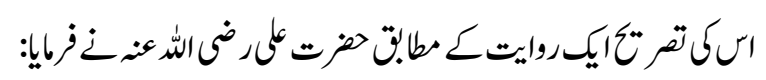

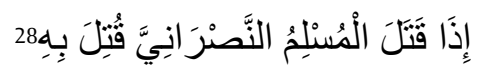

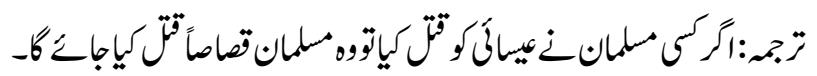

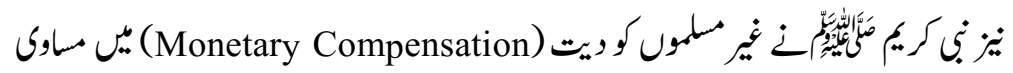

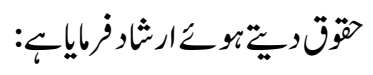

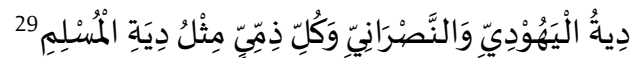

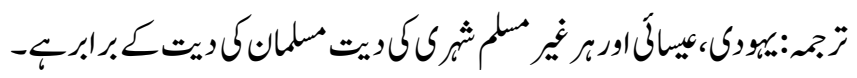

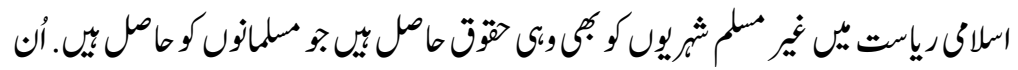

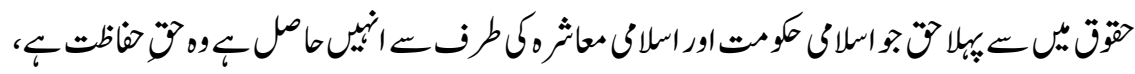

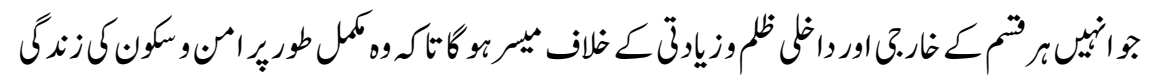




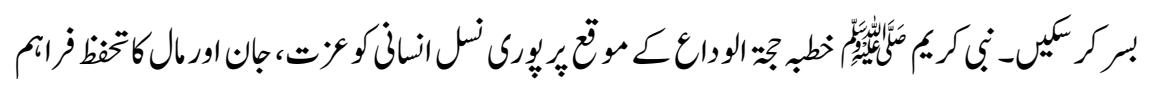

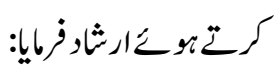

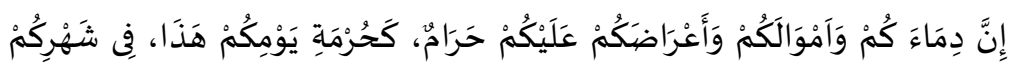

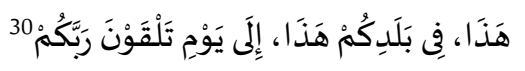

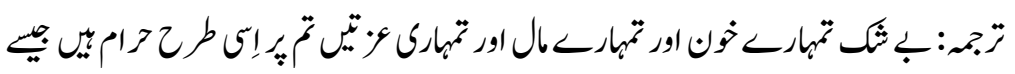

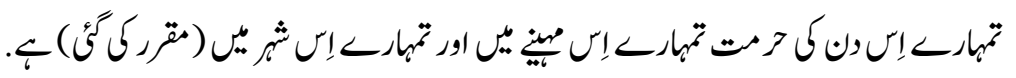

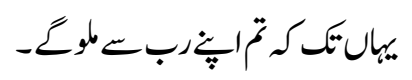

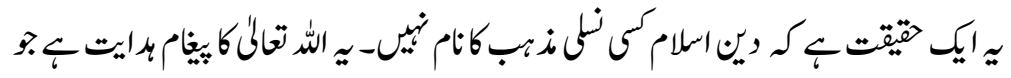

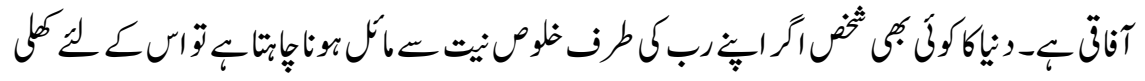

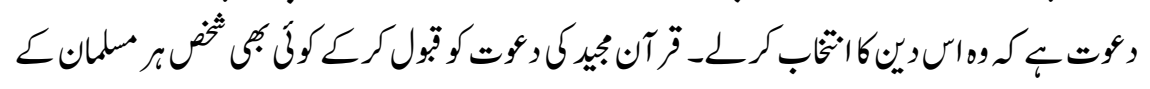

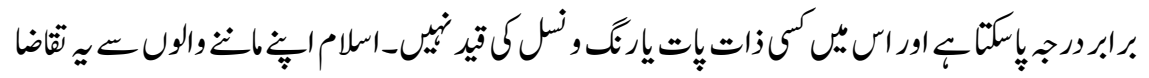

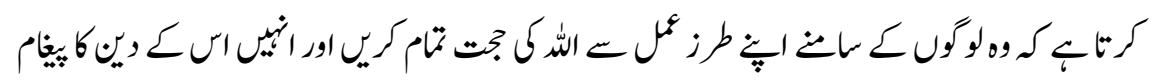

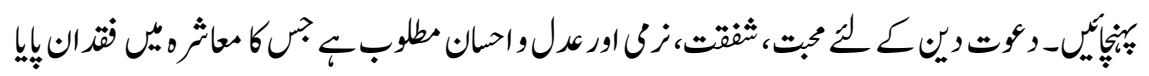

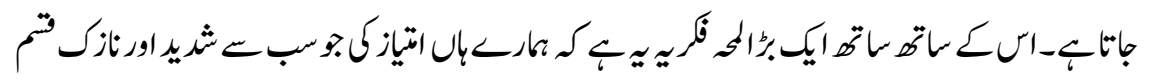

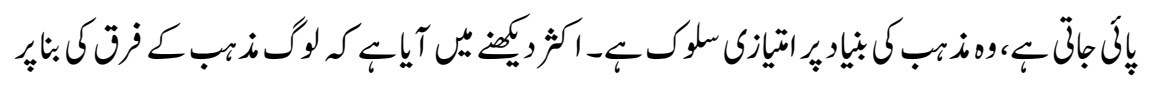

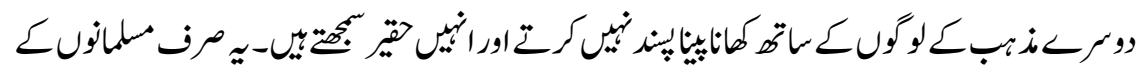

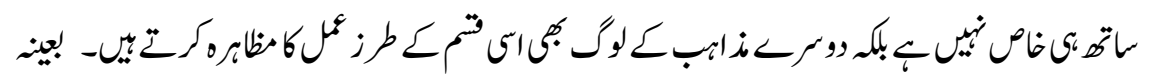

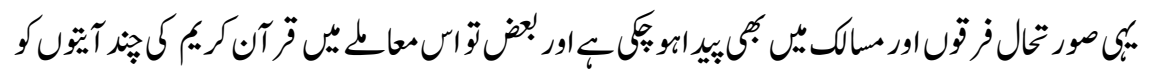

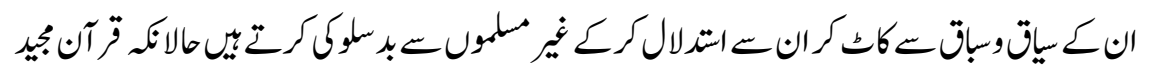

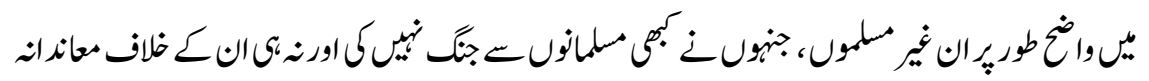

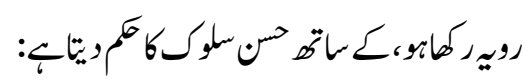

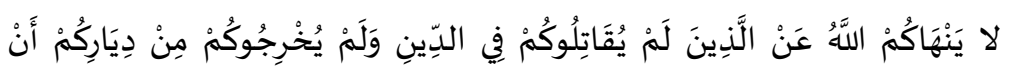

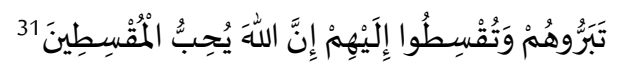




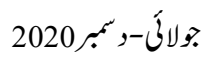

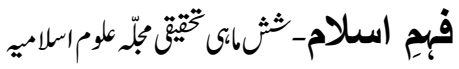

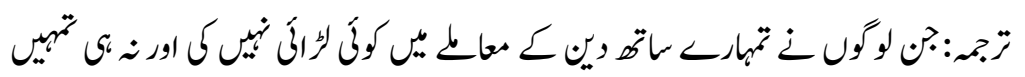

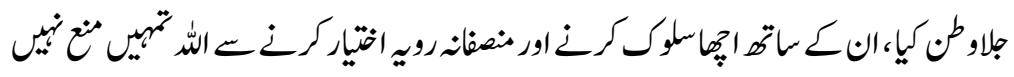

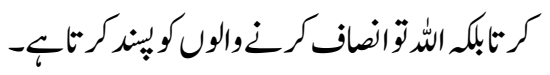

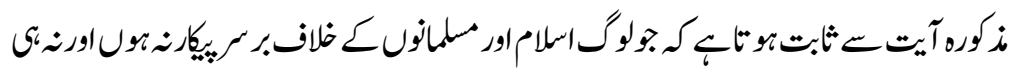

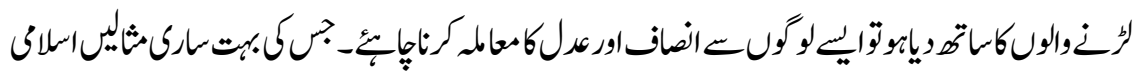

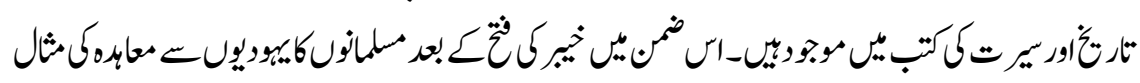

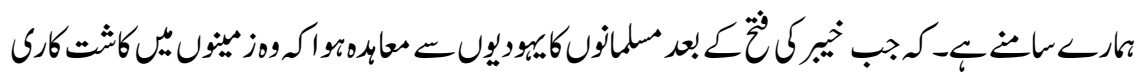

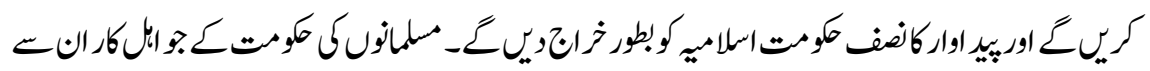

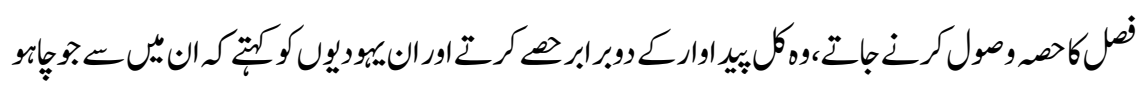

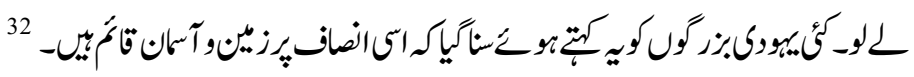

ملاصية البكث

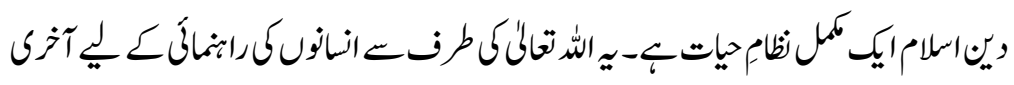

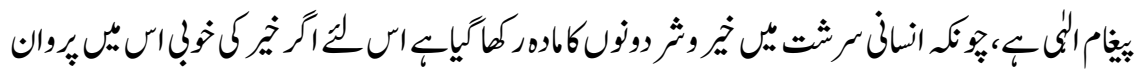

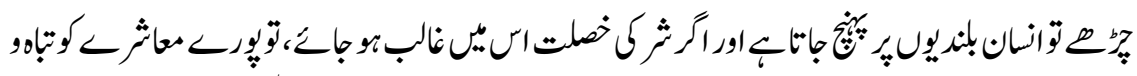

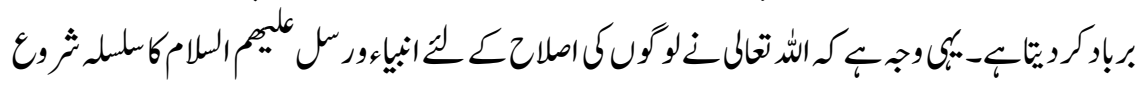

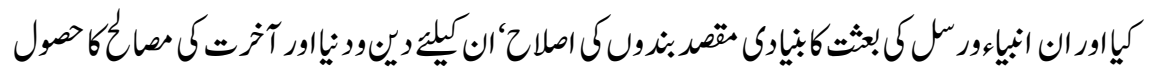

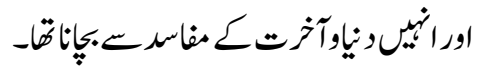

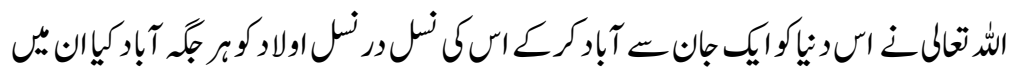

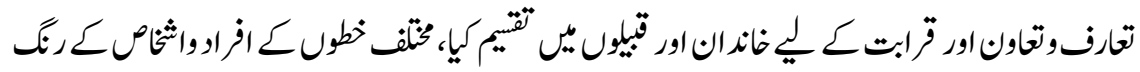

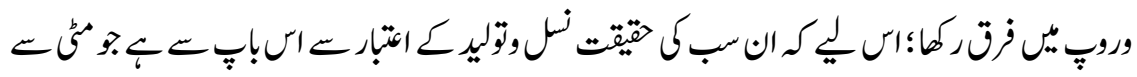

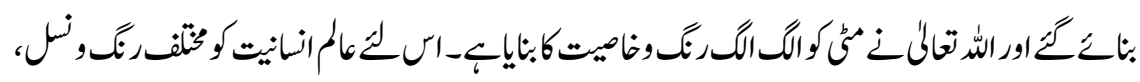

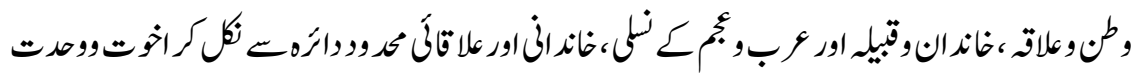

13 


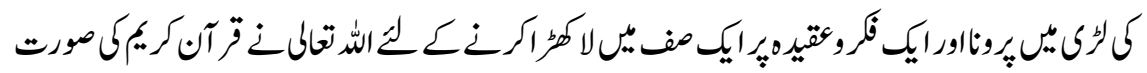

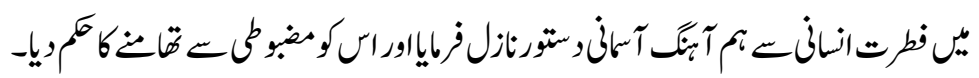

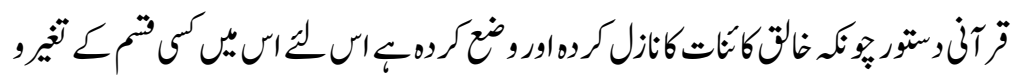

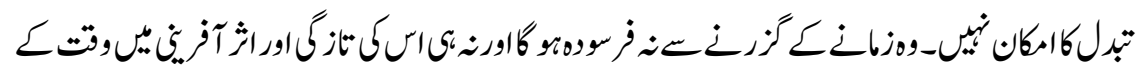

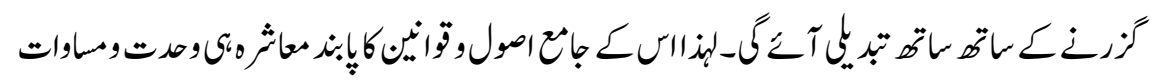

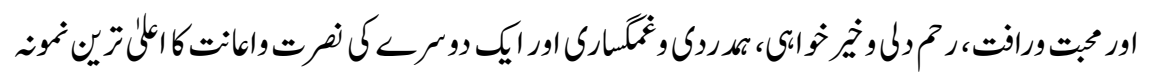

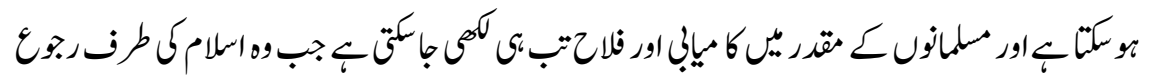

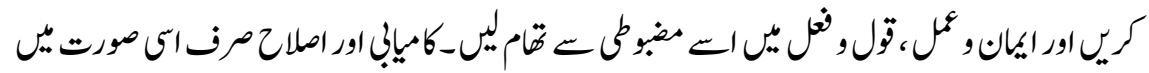

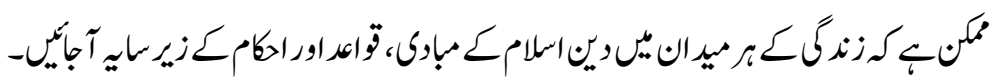

\section{كثابيات}

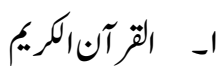

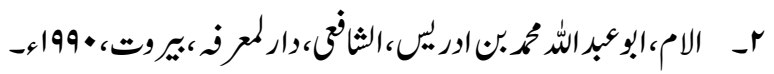

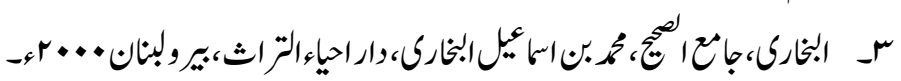

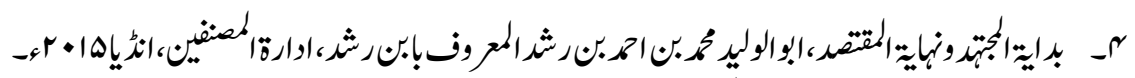

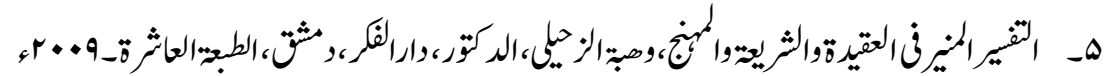

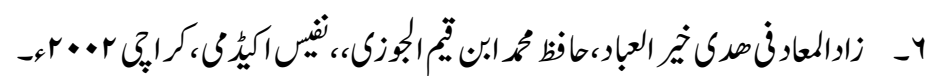

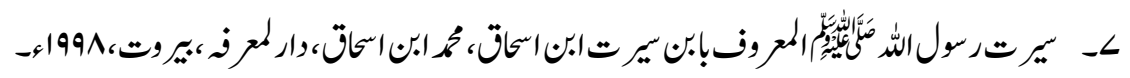

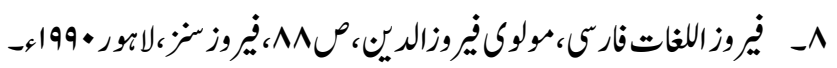

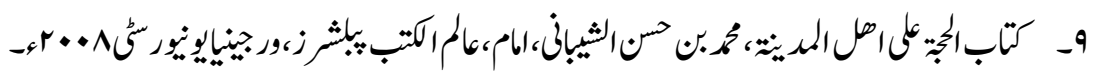

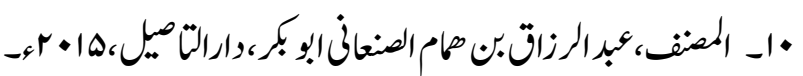

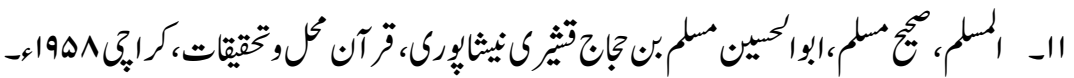

12. The Oxford English Dictionary, Prepared by J.A.Simpson and E.S.C. Weiner, Clarendon Press Oxford, Second Edition, Vol: vii, Hat-intervacum, 1989 . 
13. The Islamic Threat: Myth or Realty, John Esposito, New York: Oxford University Press, 1992.

14. The Early Muslim Empires: Umayyad's, Abbasids, Fatimid's, Francis E. Peters, Classic Publishers, NY, USA, 1978.

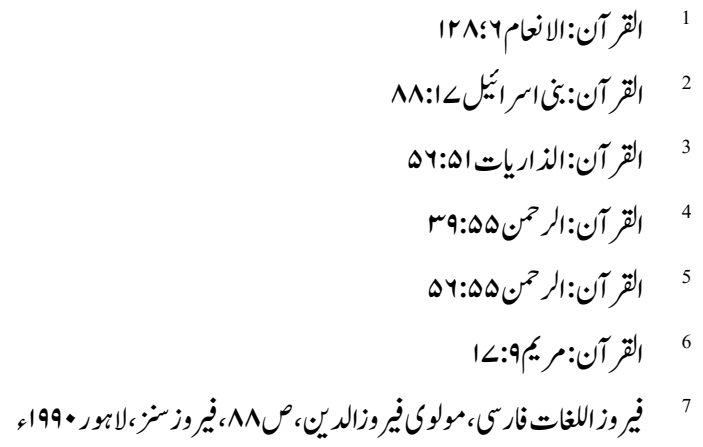

8 The Oxford English Dictionary, Second Edition, Vol: vii, Prepared by

J.A.Simpson and E.S.C.Weiner, Hat-intervacuum, page, 476-

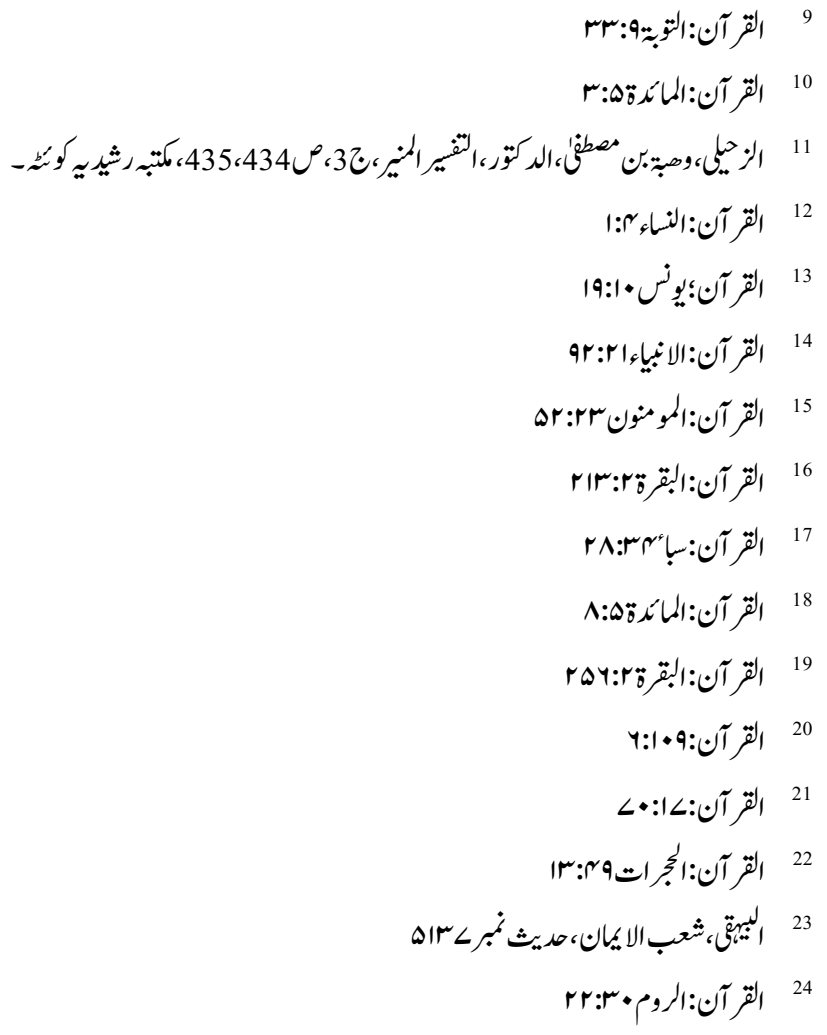




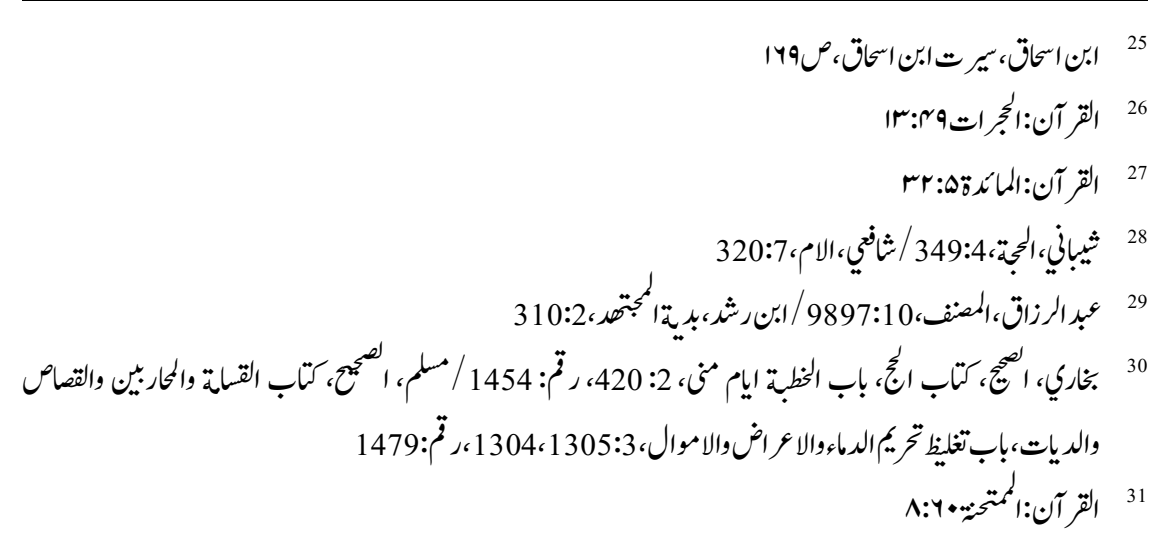

32 John Esposito, The Islamic Threat: Myth or Realty, p.174- 